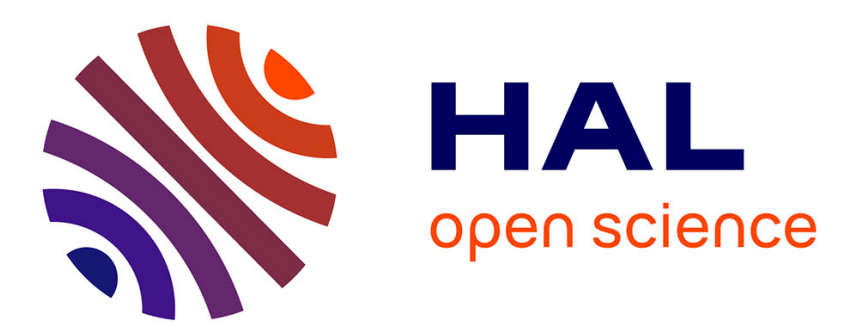

\title{
Much more than a gene: hereditary breast and ovarian cancer, reproductive choices and family life
}

Catherine Dekeuwer, Simone Bateman

\section{To cite this version:}

Catherine Dekeuwer, Simone Bateman. Much more than a gene: hereditary breast and ovarian cancer, reproductive choices and family life. Medicine, Health Care and Philosophy, 2013, 16 (2), pp.231-244. 10.1007/s11019-011-9361-9 . hal-02950332

\section{HAL Id: hal-02950332 \\ https://univ-lyon3.hal.science/hal-02950332}

Submitted on 11 Oct 2020

HAL is a multi-disciplinary open access archive for the deposit and dissemination of scientific research documents, whether they are published or not. The documents may come from teaching and research institutions in France or abroad, or from public or private research centers.
L'archive ouverte pluridisciplinaire HAL, est destinée au dépôt et à la diffusion de documents scientifiques de niveau recherche, publiés ou non, émanant des établissements d'enseignement et de recherche français ou étrangers, des laboratoires publics ou privés. 
Running head: Hereditary cancer and reproductive choices

Article type: Scientific contribution

Title: Much More than a Gene: Hereditary Breast and Ovarian Cancer, Reproductive Choices and Family Life

Authors: Catherine Dekeuwer and Simone Bateman

\section{Affiliations :}

Catherine Dekeuwer

1. Faculté de philosophie, Université Lyon 3 Jean Moulin, Institut de recherches philosophiques de Lyon

2. Centre de recherche Sens, Éthique, Société (UMR CNRS 8137)

Université Paris Descartes, Sorbonne Paris Cité

Faculté des Sciences Humaines et Sociales - Sorbonne

Paris, France

Simone Bateman

Centre de recherche Sens, Éthique, Société (UMR CNRS 8137)

Université Paris Descartes, Sorbonne Paris Cité

Faculté des Sciences Humaines et Sociales - Sorbonne

Paris, France

\section{Full address for correspondence:}

Catherine Dekeuwer

Faculté de philosophie - Université Lyon 3 Jean Moulin

1 , rue de l'université

69007 Lyon

Tel. 33-6-61-44-80-11

catherine.dekeuwer@univ-lyon3.fr

Simone Bateman

CERSES - UMR CNRS 8137 - Université Paris Descartes

Centre Universitaire des Sts. Pères

45 , rue des Sts. Pères

75270 Paris Cedex 06

Tel. 33-1-42-86-42-42 (secrétariat)

42-16 (ligne directe)

$\underline{\text { simone.bateman@parisdescartes.fr }}$ 


\section{Much More than a Gene:}

\section{Hereditary Breast and Ovarian Cancer, Reproductive Choices and Family Life}

Abstract: This article presents the results of a study that investigates the way in which carriers of a mutation on the BRCA1 or the BRCA2 gene, associated with a high risk of breast and ovarian cancer, make their reproductive decisions. Using semi-structured interviews, the study explored the way in which these persons reflected on the acceptability of taking the risk of transmitting this mutation to the next generation, the arguments they used in favor or against taking that risk, and in the light of these arguments, their opinion on the acceptability of preimplantation genetic diagnosis (PGD) as a reproductive option. The findings suggest that when carriers are planning to have a(nother) child, they are mainly concerned by the risk of transmitting 'much more than a gene': essentially painful experiences not only with respect to health, such as undergoing cancer surveillance or combatting one's own illness, but also with regards to family life, such as witnessing the illness and death of a close relative, encountering difficulties in finding a partner or reconsidering one's plans to have a family. As for opinions concerning the acceptability of PGD as a reproductive option, opinions about personal recourse were varied but all expressed the understanding that PGD should be made available to those persons who consider it their best option.

Key words: Duties to family, genetic predisposition to cancer, genetic testing, hereditary breast and ovarian cancer, preimplantation genetic diagnosis (PGD), reproductive choices 
In 2007, two French public bodies, the Agence de la Biomédecine ${ }^{1}$ and the National Cancer Institute (INCa) $)^{2}$, set up a working party to report on the use of prenatal diagnosis (PND) and preimplantation genetic diagnosis (PGD) for hereditary forms of cancer and to make recommendations for its "desirable development" (Stoppa-Lyonnet et al. 2008). This was a response to an ongoing debate about whether PGD - the genetic testing of an in-vitro fertilized embryo - should be made available to persons with genetic conditions that do not strictly qualify for access under the present legal framework, i.e. "a particularly serious disease recognized as incurable at the time of diagnosis"3. Debate focuses primarily on how strictly access to PGD should be controlled and how medical criteria to evaluate the severity of disease - age of onset, probability of developing the disease and existence of measures of surveillance, prevention, and treatments - should be interpreted and applied. Indeed, access to PGD for hereditary forms of cancer with an onset in infancy and childhood is currently available in France, whereas PGD for late-onset cancers remains highly controversial. However, some early onset cancers can be treated and therefore do not strictly qualify for access to PGD under present law. Unsurprisingly, given the attention to medical criteria and their interpretation, there is little interest in finding out how carriers of a mutation for a serious disease view their own predicament.

Hereditary breast and ovarian cancer, most frequently associated with mutations in the BRCA genes, is one such problematic indication. Mutations in the BRCA1/2 gene account for $5-10 \%$ of cases of breast and ovarian cancers. The carrier's risk of developing the disease varies from one family to another, and in certain families, women carriers develop cancer at around 30 years, a much younger age than in the general population and in other families. Even though risks to health are much higher for women than for men ${ }^{4}$, both men and women carriers have a $50 \%$ probability of transmitting the mutation to their offspring, and in some 
families, despite improvements in surveillance, prevention and treatment, the disease is experienced as so devastating and preventive measures as so radical that parents do not want to risk transmitting the mutation to their offspring. Indeed, in a recent study by Fortuny et al. (2009) of the opinions on reproductive decision-making of individuals undergoing of BRCA testing, although $36 \%$ reported that they would have children regardless of the result, $12 \%$ believed that they would not have children if they were found to be mutation carriers.

There have been numerous studies, many qualitative, on the decision to undergo testing for a BRCA mutation and the impact of discovering one's status. Some of these studies have explored themes, such as the familial dimension of this experience (Hallowell et al., 2003, 2005), the impact of gender on decision-making (d'Agincourt and Baird, 2006; Hallowell, 2006; Strømsvik et al., 2009 and 2010), and the moral dimension of motivations to test, notably responsibility for others (d'Agincourt-Canning, 2005, 2006; Hallowell et al, 2006; Rowley 2008). Fortuny and others have addressed the way discovering carrier status affects reproductive choices, and in particular opinions about the acceptability of PGD as a reproductive option (Menon et al., 2007; Staton et al., 2008; Fortuny et al., 2009; Quinn et al., 2009, 2010a and 2010b). However, most of these studies, based on questionnaires, have not allowed a full investigation of carrier reflections on reproductive issues. We have thus attempted to contribute to such an investigation, by conducting a series of semi-structured interviews with a small group of carriers of a BRCA1/2 mutation, that explores the way in which they reflect on the acceptability of taking the risk of transmitting this mutation to the next generation, the arguments they use in favor or against taking that risk, and in the light of these arguments, the acceptability of PGD as a reproductive option ${ }^{5}$.

We recruited carriers willing to be interviewed at two hospital services offering genetic testing. A letter was addressed to potential participants by the heads of each service, introducing the investigators and explaining the general objective of the study: to understand 
whether knowing that one is a carrier of a genetic predisposition to cancer affects one's reproductive decisions. Persons were invited for an interview with investigators; participation was totally voluntary and anonymity of the interview material was guaranteed ${ }^{6}$. Twenty persons, 19 women and 1 man, accepted this invitation ${ }^{7}$. Their age ranged from 30 to 62 years and 13 persons (12 women and 1 man) could be considered of reproductive age (under 45 years). Most were married or lived with a partner (16), one person was single, three were divorced. Two women among the 16 participants with partners asked us to extend the interview to include him. Fifteen persons had at least one child, and 5 persons were childless. Of the 19 women interviewed, 8 had already had one to three breast cancers and one had had ovarian cancer. Participants had received their BRCA1/2 results from 1 to 13 years before the interview, but almost three-fourths had received their results between 1 and 4 years preceding the interview $(15 / 20)$.

During these interviews, which were conducted in a flexible manner so that an on-going conversation could be established, we first asked each person to tell us about the history of breast and ovarian cancer in his or her family and to recount the events that had led to the decision to test. We then asked them to tell us how carrier status had affected their personal, familial and professional relationships and their plans for the future. We finally explored the way in which they reflected about and made reproductive decisions and solicited their opinion on the acceptability of PGD as a reproductive option, even though a BRCA1/2 mutation is not presently considered in France as a valid medical indication for PGD. All persons consented to a taped interview and analysis was based on verbatim transcriptions.

Interviews were analyzed according to a conventional qualitative approach involving the search for recurring patterns. The interviews were initially gleaned for demographic and other factual information concerning our population (sex, age, marital status, offspring, personal history of the disease, time lapse since test results - see Table 1). We did not 
systematically explore profession and educational level, although we did in many cases obtain this information in the course of the interview. Categories and themes explored through interview questions were then identified and compared: history of the disease in the family; context and reasons for taking the test; impact of test results on carrier and family; impact of results on plans to have a family; attitude toward PGD as a reproductive option. An inductive approach to the material also allowed other unexpected recurring themes to emerge, such as those related to the experience of cancer surveillance and, for women who had been ill, of treatment, as well as those related to the experience of accompanying the illness of another family member. It also allowed us to identify links repeatedly made between certain themes.

The interviews identified four crucial areas of personal reflection related to reproductive choices: (1) the decision to find out one's status with respect to the family mutation; (2) the decisions related to preserving one's health as carrier of a mutation; (3) the decision to have a child once one knows one's status; and (4) the acceptability of PGD as a reproductive option. The four areas were not necessarily addressed by the persons we interviewed in the order given above. Although the first two areas, and particularly the second, may appear to be unrelated to concerns about reproductive options and choices, the interviews revealed a striking interaction of the four areas of concern, with a common underlying issue: is it morally acceptable to transmit to one's children a genetic predisposition to cancer? As in a previous article concerning carrier evaluation of the seriousness of a disease (Dekeuwer and Bateman, 2011), and given the findings of previous studies, we were particularly attentive to the way in which one's perceptions of duties to family members affects one's decisions as carrier of a mutation and how the impact of these decisions on partners, children and relatives leads the carrier to reconsider his or her perception of these duties.

\section{Decision to find out one's genetic status}


In France, consultation with a clinical geneticist is mandatory before genetic testing. The principal benefit of testing for a BRCA1/2 mutation is presented as the possibility of setting up a program of cancer surveillance and prophylactic measures for carriers and other family members who might test positive. The impact of testing on reproductive decisions is not usually broached at this time. However, our interview materiel suggests that concerns for the next generation as well as reproductive concerns are an important aspect of the decision to test.

\section{The decision to test}

When persons recounted the circumstances in which they had decided to test, they usually brought to the fore events associated to breast and ovarian cancer. All of the women who had been ill before taking the test mentioned their own illness as the context in which they had decided to test. Persons who had not been ill identified as the circumstances leading to testing the "particularly horrible" illness and/or "extremely rapid" death of a family member, the numerous cases of breast and ovarian cancer in their family and/or the fact that another family member was considering the test. However, some persons also referred to the fact that a daughter had recently been born or that they had older children that might soon be concerned.

Concern for the next generation appears stronger when we examine the reasons persons give for taking the test. Among the women who had not developed cancer before the test, many mentioned the benefit of better cancer surveillance as their main motivation, but they often expressed concern for the genetic status of their children. For all the women who had been ill and for the man, concern for the plight of the next generation was even more manifest. The women explained that they had already had "their cancer"; so they decided to test "for their children", and noticeably not only their own children, but also nephews, nieces and grandchildren, born or to be born. The man chose the test so that he and his wife could 
"manage their family": given the traumatic experience of his sister's illness and death, both categorically refused to take the risk of transmitting the mutation, and went abroad for PGD. Other studies show that men often describe their decision to test as an obligation to their children, and many described genetic testing as a family duty (Hallowell et al., 2006; Strømsvik et al., 2009).

The expression 'for my children' refers to several concerns. First, it refers to the fear of having already transmitted the mutation. Most of the women who had had children before testing had hoped that they would not test positive, and would thus be relieved of concern for their children. The women who had daughters wanted to make it possible for them to find out whether or not they were at risk, so that they could manage their own health accordingly. But parents did not focus exclusively on health risks for daughters; they also worried about possible crises in family life (such as the illness and death of a mother or a sister) or about the difficult reproductive choices that sons as well as daughters might have to face if they turned out to be carriers. One 38 year-old mother explained that her 11 year-old son was already worrying about the risk of transmitting the mutation to his own children. Finally, as Strømsvik et al. (2010) has already reported for men, women feared that the genetic information would be detrimental to their children when choosing a partner.

For most of the persons who felt that they had not completed their families, the decision to test was difficult, given the impact a positive result might have on their reproductive choices. Only the man had explicitly linked his decision to test with the decision to use PGD and this was his only reason for testing. Most women described the situation as far more complex. Although one woman had considered taking the test to eventually have access to better surveillance and preventive surgery, she decided to postpone testing until she had had her children: she felt it was difficult to find out one's genetic status and then knowingly take the risk of passing on the mutation. Although she had known that her sister had undergone 
genetic testing before her death, she did not request further information from her brother-inlaw before the birth of her two children. She told us: "I didn't feel capable of conceiving a child, knowing I had a genetic anomaly (...) it's not an easy decision to manage; I couldn't see myself consciously taking that risk". She finally decided to test after "making a deal" with her husband: if she turned out to be a carrier, they would have no more children.

Deciding to test thus has a dual dimension that is not always clear to each person at the time of her decision: the result both facilitates access to medical care and provides information that can be useful when making reproductive choices. But genetic information is not always perceived as facilitating reproductive decision-making. For women who can still have children, it may be difficult to choose between the advantages of close medical surveillance and the consequences that carrier status may have on their plans to have a family. Furthermore, genetic testing is often considered by parents as a tool or an opportunity not only for themselves but for their offspring: if their children want to make better health and procreative choices, genetic information will, thanks to them, be available. Nonetheless, parents may eventually discover that they had not foreseen all the consequences of making this information available to their children. A 62 year-old woman, who had taken the test after falling ill with breast cancer, revealed the results to her son. He immediately underwent testing and, on discovering he was himself a carrier, categorically decided not to have children. The mother was quite upset about the impact of the positive result on her son's reproductive decisions.

\section{Handling the impact of the test result}

The dual dimension of genetic testing is again evident when carriers describe its impact on their life and that of other family members. The initial emotional impact focuses primarily on the way a positive result changes their relations to others. Surprisingly, few women mentioned 
fear of developing cancer or of having to undergo prophylactic surgery. Many more expressed feelings regarding their children: one woman said she was relieved to have had boys, and those who were parents generally expressed the fear that they had already transmitted the mutation to their children. Women were also concerned about the care that, as mothers, they believe they owe to their children. One woman reported that, given her increased risk of developing cancer, she feared she might become incapable of caring for her teenage daughter. Another said she was stricken by the test result because, if she looked at the situation from her son's perspective, he was now at risk of losing his mother.

Then followed a time of considered reflection, during which the test result was perceived as a tool for further decision-making. As the women we interviewed were all carriers, they evidently reported that the result confronted them with the necessity of close cancer surveillance and with questions about prophylactic removal of their ovaries and breasts. But for those women who chose to test before the birth of (all of) their children, the information generated doubts about pursuing plans to have or to extend their family. First, it raised questions about the best moment to have children and created a sense of urgency. One woman without children reported: "What else does it [being a carrier] imply? Well, it also implied that physicians urged me (she laughs), well, they strongly recommended that I have children because I am 32 years old”. Indeed, prophylactic ovariectomy, highly recommended for all carriers, is usually proposed at around 40 years of age, and in some cases at an even earlier age. Moreover, some women reported that the decision to have (more) children and thus accept the risk of transmitting the mutation was not self-evident and required much thought.

\section{The family messenger}


In France, the clinical geneticist has a legal obligation to inform her client that, if a familial mutation is disclosed, the person has a duty to notify other family members who might be at risk. Persons who choose to find out their genetic status are thus made aware, before testing, of the importance of the carrier's role as family messenger. Our data suggests that, in delivering information about the mutation to other members of the family, the possible reproductive dilemmas that genetic information can generate are taken into consideration.

Other studies have shown that both men (Strømsvik et al., 2010) and women (Hallowell et al., 2003) tend to postpone disclosing genetic information to their adult children when they are struggling with difficult life events. Our study confirms these results: most of the women we interviewed carefully avoided informing someone (aunts, sisters, brothers, children, nephews, nieces, cousins and grandchildren) who appeared vulnerable. Women carriers paid particular attention to their sisters and eventually their nieces and chose the best moment to give them the information. They took into consideration the professional and personal situation of their sisters: whether or not she was still a student, whether she was single or married, whether or not she had children. If there was no immediate medical urgency, they were unwilling to give information to sisters and nieces who were not in a stable relationship. Some even decided, in a way that could be considered contrary to a person's right to liberty and reproductive autonomy, to delay transmitting information until the sister or niece had had her children. However, some women felt that revealing their genetic status to their children was imperative, because it obliged them to face up to the difficult situation affecting the whole family. In the light of available relevant information, these mothers experienced conflicting obligations to protect and care for their children and to confront them with a situation that called for responsible reflection and decision-making.

In managing these situations, messengers therefore take into consideration a family member's situation with respect to childbearing. However, protecting what they believe to be 
the best interests of the each member does not always imply that health issues and reproductive issues can be easily reconciled.

\section{Decisions regarding one's own health}

Previous studies have emphasized that women's personal experience of breast and/or ovarian cancer has an influence on their opinions regarding the acceptability of PGD (Menon et al., 2007; Staton et al., 2008; Fortuny et al., 2009; Quinn et al., 2009). Our study suggests that a part of this experience was clearly related to the types of treatments they had had to undergo. Women whose cancer was detected early and who did not undergo chemotherapy tended to play down breast cancer's reputation as a severe disease. A 41 year-old woman who developed breast cancers at 34, 36 and 39 years and was treated by surgery and radiotherapy, explained: "I don't think I have ever considered myself as being ill". On the other hand, women who had had chemotherapy reported that it was an extremely trying experience, with significant impact on their appearance and normal functioning, sometimes obliging them to stop work.

However, there is also a conjugal and familial dimension to that experience, in which the quality of family relationships before and after a woman develops cancer plays an important role. A 36 year-old woman, mother of a six year-old daughter, felt ashamed of her breast cancer and her carrier status in front of her husband and her parents-in-law. Her cancer had developed when she and her husband were planning to have a second child. She explained: "The family urges you to have a second child (...) I remember, my mother-in-law would say: 'I dream of having lots of grandchildren'”. Her husband was supportive during her treatments, but he now wanted a second child whereas she felts a pregnancy might be a threat to her health. Furthermore, she worried about the shame an adult carrier child might feel in a 
relationship with his or her own partner. Consequently, she wondered whether it was acceptable to take the risk of transmitting the mutation to a second child.

Little attention however has been given to women's experience of surveillance and prevention or to the effect that the strategies women devise to safeguard their health may or may not have on their reproductive choices. Our interviews reveal that women's health care strategies vary considerably, but suggest that their choice of a more or less radical strategy to protect their health is correlated with their views about the acceptability of taking the risk of transmitting the mutation.

\section{Surveillance}

Women who had been ill did not talk much about surveillance measures, but many reported stress and continuous fear of a relapse or another cancer. Women who had not had cancer began surveillance measures after testing positive: they reported regular mammography, MRI and ultrasound scans, usually every six months. Depending on the time that had elapsed since receiving test results, the women we interviewed had had between one and at least twenty series of examinations. They reported different levels of anxiety and stress due to regular surveillance. For some of them, it was simply a necessary regular check-up: one woman compared it to regular car maintenance. Other women, however, mentioned the anxiety generated by MRI or the need to be accompanied by their partner or a close relative to help them endure the series of examinations. Noticeably, as the years of surveillance increase, the women express more stress and anxiety. Some women who had never had cancer reported that, even after only one or a few surveillance procedures, waiting for a doubtful MRI result was so worrying that they had finally preferred to undergo prophylactic mastectomy and breast reconstruction. These women also reported having difficulties in deciding to have a(nother) child. 


\section{Prophylactic mastectomy}

The data gathered in this study suggest that the decision to undergo prophylactic mastectomy is influenced by three major factors: a woman's lived experience of cancer and cancer treatments, the experience another family member has had with the disease, and concerns for the impact of mastectomy on one's partner and one's children.

Almost all of the women who had had ovarian or breast cancer considered prophylactic mastectomy as a self-evident preventive measure, even if they experienced mastectomy as a severe mutilation and were fearful of the surgery. These women wanted above all to avoid chemotherapy and death. The more trying their experience of the disease, the more selfevident prophylactic mastectomy appeared. Only one woman over 50 explained she was not in favor of prophylactic mastectomy: diagnosed by surveillance measures at the earliest stage, her breast cancer had been treated only by surgery.

Among women who had never had cancer, there seemed to be no common opinion regarding the benefit to be gained from mastectomy and breast reconstruction as a preventive measure. In fact, some women reported that physicians themselves were divided on this question. Interview material suggests that these women's opinions are related to several factors: their own evaluation of the statistics concerning the medical benefits of mastectomy, the links they establish between having breasts and being a woman, the regret they may experience if they develop a tumor, and the experience other family members have had of the disease.

When women considered mastectomy, they took into account the impact it might have on their family. Most women mentioned the negative perception both they and their partner had of the operation; some felt that their partner really had no choice, given that their life was at stake. Some women also talked about the way their children had reacted to the decision. A 
38 year-old mother of two boys explained: "If I had taken my children into consideration, I would not have undergone the operation because I knew it would generate stress." She believed that she had made a selfish decision short-term, even if in the long run it was better for the "protection of the family". This same woman also told us about the operation's impact on her 11 year-old son:

\footnotetext{
“He said to me: 'Well, listen: I know that there isn't any risk for me but, if I have the anomaly, I can transmit it to my children and if I have a girl, she will have to endure what you are enduring now, they [physicians] will have to remove her breasts, that's not too great. Mother, what I see is that it's not easy for you. So you see (...) I will have to be very careful later on, not to have a daughter."”
}

In deciding for prophylactic mastectomy, mothers are protecting their health but they are concomitantly shaping their children's familial experience of cancer and ultimately influencing their children's reproductive choices.

\section{Prophylactic ovariectomy}

Most women underwent prophylactic ovariectomy or planned for it around 40 years of age, and sometimes around 35 for more security. This decision creates problems especially for women who have not had children. However, our interviews suggest that ovariectomy could, despite appearances, be a crucial matter even for women who have already had children, because they have to reconsider their plans to have a larger family.

Three women aged 37, 40 and 41, who had or did not have children, did not mention ovariectomy during the interview. For example, the 40 year-old woman, mother of a 13 yearold boy and a 3 year-old girl explained that she had wanted to have three or four children. She had initially given up this idea because her son had been born with another serious genetic condition. But she had since been able to have a daughter after PGD and, at the time of the 
interview, she was wondering whether she was willing to endure another IVF procedure to have a third child. Prophylactic ovariectomy probably created, for these women, such a painful dilemma that they did not wish to talk about it.

Several women who had planned to have three children explained that they had since resolved to settle for two. One 34 year-old woman, expecting her second child, recounted how medical necessity had affected her procreative options in the future:

"Of course, it's true that the removal of the ovaries, once one has had one's children, is not a problem. But it is also true that it involves some mourning because I must admit that at 40 years of age, I will no longer be able to say : hey, I'd like to have a third child. Even if it is true that one often hears about blended families, I know that this is something that will not happen to me."

Moreover, prophylactic ovariectomy creates constraints that also have an impact on a couple's relationship. A mother of two children reported that she still "feels badly", three years after the operation, when she is around babies, especially with regards to her husband who loves babies and would like to have had three children. A couple's stability can also be threatened by time constraints on their plans to have children: a 32 year-old woman without children reported that she had become "obsessed by time".

Finally, the consequences of prophylactic ovariectomy for personal and family life was considered by some as so substantial that a 46 year-old woman, firmly opposed to PGD, reassessed her position when considering the case of women in families where tumors develop at such an early age that they are obliged to undergo ovariectomy before they have had children. In this case, she felt it would be legitimate to undergo PGD to avoid transmitting this unfortunate situation to the next generation.

Pregnancy: a cancer risk? 
As Staton et al. (2008) have pointed out, younger carrier women must manage two concerns the care for their health and the desire to have children - often in the absence of optimal evidence about the benefits of preventive measures. Our study also suggests that the absence of a clear medical consensus concerning the risk associated with pregnancy or IVF for carrier women (Pagani et al. 2011) is translated by women into the possibility of following their wishes or playing into their fears.

The very possibility of becoming pregnant sometimes becomes a major preoccupation for the women we interviewed, either because physicians recommended they momentarily avoid pregnancy, or because women feared possible risks to health or felt they were running out of time. One 41 year-old woman with no children reported that she had become pregnant between her first and her second breast cancer, but given that she was undergoing radiotherapy for the first cancer, physicians vehemently suggested she abort. She must now take hormone therapy for two more years and explained: "It's not when I'm 43 that they [physicians] will suggest I have children". She stressed that the medical team should take into account a woman's reproductive history when treating the patient.

Some women considered pregnancy itself, in particular pregnancy by IVF, to be a risk. One young woman who had developed cancer reported that, although she knew there was no consensus among the physicians on the matter, she remained fearful of becoming pregnant. A 30 year-old woman, who had decided on prophylactic mastectomy at the age of 26 , said that PGD would be a good solution for her, as she could thus avoid transmitting the mutation. But she believed this would be impossible because ovarian stimulation reputedly increases the risk of cancer. In the absence of medical consensus, these women followed their fears.

Nonetheless, two of the women we interviewed had had a child by IVF. Their views concerning the risk associated with ovarian stimulation for an IVF procedure contrasted with what they reported as being the position of some physicians, but only one woman reported 
that her genetic status had had an impact on her medical itinerary. After deciding to test for carrier status, physicians told her that IVF would be impossible if she turned out to be a carrier, but they finally gave her permission for two IVF cycles and no more. This woman wanted a child so badly that she had asked for information in another IVF center. She reported that physicians at the second center had seen no contraindication for IVF in her case. This woman's desire to have a child far exceeded fear for her health.

Women's surveillance and preventive strategies are thus quite complex, because they take into consideration not only each woman's concern for her health and for the appropriate timing of prophylactic measures, but also concern for the impact of these strategies on her family. From this perspective, the boundaries between the experiences of women who have had cancer and the experiences of those who have not tend to disappear. Furthermore, the stress generated by cancer surveillance and the weightiness of decisions regarding preventive surgery, as well as the difficulties related to a pregnancy in this context, provide women with many reasons to want to avoid the risk of transmitting the mutation to the next generation.

\section{The decision to have a child}

During the course of the interview, we raised the question as to whether being aware of their carrier status had had or might have an effect on the decision to have a(nother) child. Persons responded by considering whether or not taking the risk of transmitting the mutation was acceptable. They reported different views on this issue, but what was most striking was that they linked this issue and the decision to have a child with concerns regarding the impact of carrier status on their capacity to fulfill their role as parents, their plans to have a family, and a unique equilibrium - occasionally a tension - between their desire to have children and a sense of responsibility for their reproductive choices and their ultimate consequences. 


\section{Lessons from the older generation}

The seven women who had already had their children and who undertook genetic testing after the age of 45 emphasized the extreme difficulty of answering the question: "What would have been my decision had I known?" Two women felt that combatting their own illness was much more bearable than the suffering they would experience if their daughter were to develop cancer. One woman said: "I can overcome what concerns me, but it is difficult to bear the fact that persons I love are ill, not well in their minds and in their bodies. You can imagine how much stronger this would be if it were my daughter, my own child." This is the reason both women put forward to explain why they would probably have preferred PGD to taking the risk of transmitting the mutation to their children.

Older women also highlighted the peculiar situation facing their carrier children: the possibility of finding out their status through genetic testing would entail unprecedented difficulties in making their reproductive choices. Some of them expressed relief not to have been confronted with this delicate situation. Indeed, some of the younger persons we interviewed also gave us this argument to explain why they preferred to avoid the risk of transmitting the mutation, either by not having (more) children or by resorting to PGD: they were concerned about the difficult procreative decisions their own children would have to make if they turned out to be carriers.

\section{Carrier status and responsibilities as caretaker}

In our study, a woman's appraisal of the acceptability of taking the risk of transmitting a BRCA1/2 mutation did not seem to be linked to the fact that she had or had not developed cancer: the risk seemed no less acceptable to women who had had breast or ovarian cancer than to those who had not. However, when women became aware of their carrier status, they 
considered the impact of that fact on their responsibilities as caretaker. They asked themselves: should I have a(nother) child, given that I may fall ill and might consequently not be able to take care of her/them? Some of the women who had not developed cancer decided to have no more children, or to have fewer children than initially planned. A mother of a 6 year-old daughter who had developed breast cancer also reported such hesitation. Her chemotherapy having ended four years ago, physicians had told her that she could now have a baby. But she explained that if she has a relapse or develops another cancer, she would not be able to care for her children. Moreover, if she dies, she would no longer be there to explain to her daughter(s) how to deal with discovering carrier status, being ill, enduring treatments, and all the weighty consequences these events have on conjugal and family life.

\section{Planning to have a family}

Reflecting the findings mentioned above by Fortuny et al. (2009), the women in our study said that neither the test result nor the disease changed their "plans for a family". Indeed, discovering one's carrier status as such does not seem to have a systematic effect on a person's decision to have a(nother) child. Among the 13 persons under 45 years of age, 8 had one or more children at the time of the interview. Only one woman had simply decided to have all her children before genetic testing. Another woman had had her first child after learning about her carrier status and now wanted to have a second child. The remaining five women and the man had conceived their first child before learning about carrier status. Two of the women had since decided to have another child and were pregnant at the time of the interview. Two others were undecided as to whether or not they should have another child. The fifth woman and the man decided to opt for PGD to conceive their second child and, for the man, also his third child. Our interview material suggests that the decision to have or not to have a(nother) child after finding out one's carrier status will depend on whether or not a 
couple had made previous plans to have children and on how these plans were affected by their perception of the acceptability of the risk of transmitting the mutation to their offspring.

When persons had previously made well-defined plans with their partner to have a family, the decision to have more children was said to be self-evident. They sometimes referred to these plans to explain their decision to take the risk of transmitting the mutation. For example, one pregnant woman explained:

"Our plans to marry and then to have children, all of that was well-anchored (...) No matter what, we wanted to have children (...). We had decided that we did not want our daughter to be an only child, so we wanted a second child. So this [carrier status] has not changed our wish to have another child, even if there is a risk of transmission".

Our interview material suggests that plans to have a family are the object of much personal investment and convey expectations of what each person believes is a good family life. These plans therefore seem to function as a point of reference when a person is confronted with bad news.

Whereas these plans were for some persons a sufficient reason to take the risk of transmitting the mutation to a(nother) child, plans for a family prompted others to find alternative solutions when they felt that taking that risk was morally unacceptable. In both cases, the decision to have children was said to be self-evident. The man we interviewed met his wife when he was 18 years old. They decided to marry and have a large family; he described a closely knit couple and explained that he and his wife loved each other very much. He turned out to be a carrier but, because they wanted a big family, they decided to go abroad twice to undergo PGD.

The decision to have (or not to have) a child also seems closely related to the extent of a person's involvement in and commitment to the couple's plan to have a family: these translate not only the amount of time and effort invested in that plan, but also a couple's joint capacity 
to deal with carrier status in making their plans to have a family. A 30 year-old woman who had had a first child through IVF explained that when one chooses this solution, it is precisely because one wants a child so badly. She told us that, despite the fact that they both really wanted a family, her partner was prone to give up, and she had to struggle against his discouragement. Being a carrier of a BRCA mutation was thus in her view practically nothing compared to that project and the involvement it required. At the time of the interview, she had developed cancer and was undergoing chemotherapy, but she reported that she would like to give her daughter a sibling. She added that if PGD were permitted by law in France, she would probably opt for this solution to avoid transmitting the mutation. But if PGD resulted only in BRCA carrier embryos, she would want them implanted anyway. Another 32 year-old woman who had not had cancer, met her partner after having chosen to find out her genetic status. She explained that she had built her relationship with him on the basis of that knowledge. She immediately told him that she was a carrier of a BRCA mutation, that she wanted children and had to hurry up and have them. "He accepted everything", she told us. She said that the mutation "has become a part of our relationship without making things gloomy".

The decision to have another child was not self-evident for all carriers: some women reported that that decision was now far more difficult. In these cases, women disagreed with their partners about how the new situation impacted their plans to have a family. For example, a woman described her husband as very insistent about having another child and explained that he did not seem too concerned about her increased risk of developing another breast cancer. As there is insufficient data concerning the correlation between pregnancy and the risk of cancer for carrier women, she reported: "He says: 'Well, in this way, you will be helping the advancement of science'. Ah! that's a bit rough...." He also refuses to consider the risk of passing on the mutation, "whereas $I$ ask myself that question", she stressed. The disagreement 
between partners was so strong that she was afraid their relationship would fall apart, and was therefore quite ready to have another child in order to keep her husband.

The ordeal of being ill and the risk of transmitting the mutation were often mentioned as factors leading to a separation. Some women reported that their sister's or niece's couple exploded when these women discovered their carrier status. Moreover, difficulties in having a child may be a real challenge for some couples. A woman explained that she was aware of her partner's deep desire to be a father. Unfortunately, as a consequence of chemotherapy, she can no longer have children. She told us:

"In fact, we are constantly on the brink [of separating] even if we are very close! And it's true that I have a marvelous husband! (...) Because he could very well have rebelled or left and said: 'Well, You can't have children! I want children! I'm leaving you and will set myself up with someone else!' That's just about his only option. And there, a while ago, he said: 'As for me ... She is my priority!' So there are no children? There are no children! I must say, that is quite rare."

However, neither the fact that a woman had or had not developed cancer, nor one's commitment to and involvement in a plan to have a family was enough to explain a person's decision to have a(nother) child despite the risk of transmitting a mutation.

\section{Desire and responsibility}

Persons reported that their decision to have a child brought into play both their desire to have children and the feeling that they must assume responsibility for the decisions they make and their ultimate consequences. Deciding to have a child was therefore more or less difficult according to whether or not persons experienced tension between these two feelings.

The persons we interviewed did not have much to say about their desire to have a child except that some felt it was strong enough to make it worth taking the risk of transmitting the 
mutation. A person's desire for a child was often perceived as an end that was good in itself. As one woman said: "What is the most beautiful thing one can do? For me, it's having children; it is the most marvelous thing we can do on earth, so why deprive ourselves of such happiness?" For many of the persons we interviewed, a good and happy life is a life with children; it is thus worth taking the risk of transmitting the mutation.

If the desire to have children seems to fuel plans to have a family, they are not the same thing. A desire to have children is personal whereas planning for a family takes into account the partner's desire and the well-being of children already born. Moreover, our data suggests that plans to have a child are modulated by familial experience: in spite of their desire to have another child, some persons reported that they had taken into account how things had gone with their first child in postponing, giving up or adjusting their plan for second child.

The interviews also clarify why carrier status generates new challenges to a parent's sense of responsibility. First, by accepting to take the risk of transmitting a mutation, a person's responsibility is at stake because, as a parent, she will eventually have to justify this choice to her children. A 30 year-old woman, who had had a miscarriage one week before the interview, decided to find out her genetic status when she was 25 years old, shortly after her mother's death from cancer. At the time, she was already married and had planned with her husband to have children, but not straightaway. After becoming aware of her carrier status, she decided to undergo prophylactic mastectomy and planned to have prophylactic ovariectomy at the age of 35 . She recounted that her plans to have a family have since been adjusted to this reality. Indeed, she wondered:

\footnotetext{
"At the very beginning, when I learned about the mutation, I said to myself: I'm not sure I will have children. Can I really impose the gene on them? That was my concern. Even if there is a $50 \%$ chance that the child will have the gene and a $50 \%$ chance that he won't. But then later on - that was my great dilemma - will he hold this against me? That I conceived him with full knowledge of the risk?"
} 
In a survey of carrier women, Quinn et al. (2009) found that a subset of respondents thought that women who chose to have children knowing that risk were 'irresponsible'. Our data also gives information about the extent to which parents or future parents feel responsible for the consequences of the decisions they make. The persons we interviewed felt they were ultimately responsible for the possible harmful effects of a deleterious mutation on their children: not only their possible illness and death but also the problems their children might have to face as adults in caring for or losing a close relative, finding and keeping a partner and making plans to have a family. However, this sense of responsibility is not necessarily associated with the idea that parents will be held accountable for the consequences of their decisions by their children. Some persons felt it was simply their duty as parents not to take the risk of passing on a harmful gene. One woman clearly attributes a moral dimension to this responsibility: “There is a gene that isn't fit to be had. So, morally, I feel that I shouldn't pass it on! Let's say that it is a moral duty not to transmit the gene."

Being aware of one's status as carrier of a deleterious mutation thus has consequences on the person's decision to have a child. Some persons feel that the mutation's potential for harm is significant but uncertain and may be counterbalanced by the good of having a family and by the possibility of finding solutions to such harm in the future; carrier status therefore does not justify changing plans for a family. But many persons feel they must (and will) be held accountable for decisions that affect both themselves and their offspring with respect to the medical and familial problems that a carrier's condition involves; in some cases, they may feel they should have no (more) children.

Thus with each decision to have a child, the initial balance between desire and responsibility underlying a couple's plans to have a family is updated and the couple's plans eventually modified. This balance can be upset by fears for the carrier's health, new worries about the well-being of children already born and duties regarding their care, and possible 
disagreements between partners about how plans for a family should or should not be changed.

\section{The acceptability of PGD}

The question concerning the acceptability of undergoing PGD to avoid the risk of transmitting a genetic predisposition for hereditary breast and ovarian cancer was raised when persons wondered about the reproductive choices they had made or would have had to make had PGD been available when they had decided to have children, or would eventually make if PGD for late onset hereditary cancers were allowed in France. Of the 20 persons we interviewed, two had never heard of PGD. Five persons said they would not choose to undergo PGD. Six persons expressed uncertainty. Seven persons would choose this option, and two of the seven had indeed made this choice.

When persons under 45 years were considering the acceptability of PGD, they first talked about themselves and developed their thoughts in the context of what was possible for them. Some of them tended to quickly evacuate the subject, because PGD was medically impossible in their case. Others expressed worries about having to go abroad and the material and physical constraints associated with PGD. A 30 year-old woman with no children stressed the positive effect of having time to think about what she would do whereas other women in their middle and late thirties deplored a lack of time. The fact that these persons spoke about their specific personal and familial situation did not keep them from discussing the issue more generally. Confirming previous studies (Menon et al., 2007; Fortuny et al. 2009; Quinn et al., 2009), all but one woman explained that even though they might not personally opt for PGD, they felt this option should remain open to others, and particularly to their children. Moreover, if some considered the acceptability of undergoing PGD for a BRCA1/2 mutation a "delicate" 
question, they all without exception were able to think of particular cases that might justify undergoing PGD.

\section{A personal decision}

We noticed, first, that no mother expressed an opinion about what her child should decide concerning PGD. Of the seven women older than 45 years, one reported that she would probably have opted for PGD or adoption. She stressed the fact that her daughter would make her own choices, but she seemed worried about her daughter's situation and would have preferred to have been able to avoid it, had this been possible. Another woman did not know what her choice would have been regarding PGD, but spoke throughout the interview of what she considered a much more important topic: her carrier son's decision not to have children. Although she considered PGD an appropriate option for him, she did not wish to discuss it as the choice would be his own. What she most wanted was to express her distress about the fact that her son's choice was being constrained "by the gene". These concerns about the reproductive choices of the next generation were also expressed by mothers of younger children who were not yet aware of their genetic status. One woman explained that she herself would not have opted for PGD, but that it would eventually be a good option for her daughter who was 16 years-old at the time of the interview. She reported with hope: "Maybe, when my daughter grows older, the law will have changed".

The difference between a parent's and a grandparent's views of PGD as a reproductive option was also mentioned by older and younger women alike. This may contribute to explain why women report that even though they might not personally opt for PGD, they believe this option should remain open to others. One 34 year-old woman who had already had a child and was pregnant at the time of the interview explained that, even if PGD had been available, she 
would not have chosen this solution to conceive her second child. However, she reported a recent conversation with her father from whom she had inherited the mutation:

"He said to me: 'You know, if you become a grandmother, you may feel differently about this'. He, of course, sees things as a grandfather and I believe that if I had asked him for his opinion, he might (...) have said to me: 'Do it'. Whereas I don't see things that way. And it's possible that when he was a father, he may not have wanted to [opt for PGD] at the time. But I do think that for my children things may be different. In any case, for me, it's not possible."

She went on to explain that she would perhaps try to convince her children to undergo PGD, but she obviously felt highly uncomfortable with the idea of having to be the one to make such decision.

\section{Accepting or changing destiny}

Reflections about the acceptability of PGD were linked to views regarding "nature" or "destiny". Indeed, one woman we interviewed recalled that we are all carriers of genetic diseases and explained that we must "let nature take its course" or, as another woman put it, we should "just let things happen". Hallowell et al. (2006) has also reported that carrier men adopt a fatalistic explanation of transmission: it is genes, controlled by fate and destiny, rather than individuals that are responsible for the risk. However, our study suggests that if carriers refer to destiny or nature, or more generally to events beyond their control, they do so in two different ways.

Staton et al. (2008) and Quinn et al. (2009) reported that some carriers were strongly opposed to PGD, because had PGD been available to their parents, they would not be here today. They are happy with their lives, even if they are at risk of developing cancer. In our interview, women who used this argument linked it to considerations about destiny. The woman just quoted in the preceding section explained that, had her parents had the choice, she 
might not be here and thus concluded that she also had to take that risk, as had her parents. Of course, she is not really in the same position as her parents: her parents were not aware of the risk of transmitting a cancer predisposition whereas she is aware of that risk and has a choice. But she wonders if she really has the right "to choose the life of a child". She explained that she believed in letting "destiny" takes its course and destiny had resulted in her being here, as many other children on earth.

Another woman told us that, before the death of her mother and before becoming aware of her carrier status, she lived with a man who couldn't imagine himself being a father. His father had had psychiatric disorders and had developed cancer; he had died prematurely and his son was quite sure that he would pass these problems on to his children. This woman decided to end the relationship after her mother died; she described her position as the "opposite" of that of her former partner: "One must make an effort to accept life with its imperfections". Life seems to play the same role in her thinking as did destiny for the preceding woman, and she also introduces a reference to her place in the family chain. She told us that she had very much wanted to give grandchildren to her mother because she had not known her own grandmother.

For these women, the availability of PGD as a reproductive option raises a moral issue about how one should reconcile transcendental causality, one's parents' choices and one's own personal choices. Indeed, these women feel that, in making their reproductive choices, they have to come to terms both with whatever is at the origin of their own life and beyond their control and with the events, problems and decisions in their parents' lives.

Conversely, for some persons, PGD is a way of breaking loose from the hazards of the genetic lottery and of relieving their children of the burdens related to carrier status. One woman's partner would have been delighted to have the choice to decide "what should be", had they been able to have children. Another woman would prefer opting for PGD rather than 
letting the genetic lottery continue. She asked: "Why should things stop [without PGD], given that this has been going on for generations? I don't really believe it's possible." Because transcendental causality was conceived here, not as a principle that presides over each unique existence but as a blind lottery, PGD was conceived as a way of avoiding its perils.

The interview material also shows two different ways of dealing with the knowledge of one's carrier status: one that appeals to choice and the other to an order of things. For some persons, knowledge changes everything because it makes us responsible for taking the risk of transmitting the mutation and thus for a part of the child's future. One person explained that it would be illogical and almost cruel to encourage someone to find out her genetic status and then not allow her to undergo PGD if she so desired. Knowledge is the beginning of action against the genetic lottery. But others reason differently. For them, knowledge has no impact on one's choice to have children. One woman explained:

"It is indeed a risk one takes, being pregnant without knowing whether or not the baby will have the genetic mutation. In the same way, the child may also turn out to be the carrier of a disease that we did not know about to begin with."

In other words, if one has decided to let things happen, then knowledge will not make a difference.

Opinions about PGD thus vary according to one's conception of "destiny" or "nature". When one considers that a certain order of things has to preside over the conception of each unique individual, being aware of one's genetic status is of no use. Conversely, when one considers that there is only a blind genetic lottery, finding out one's genetic status is the first step in changing the course of things.

\section{A better way of having children?}


About half of the persons we interviewed raised the question of eugenics with respect to PGD. Sometimes the word "eugenics" was not used, but persons spontaneously associated PGD with the idea of conceiving a child with "blue eyes" and "blond hair". Nonetheless, for almost all the persons we interviewed, no doubt was possible: opting for PGD to avoid transmitting a breast and ovarian cancer predisposition had nothing to do with designer babies. In the scholarly literature, this distinction is labeled negative and positive eugenics. Our interview material suggests that another distinction might be more pertinent for analyzing the acceptability of PGD: indeed, PGD appears either as the only way one may be able to have children or as a better or preferable way to have a child.

PGD was perceived as the only way to have a child by persons who considered that taking the risk of transmitting the mutation was absolutely out of the question. The man we interviewed explained:

"There are people who suffer from not being able to have children. There are people who refuse to have children because they are afraid of transmitting the mutation. There are people who suffer and we must listen to their suffering, which is probably justified in most cases....Indeed, in families like mine, we realize that all the women have fallen ill, and at younger and younger ages. And the chances are extremely slight that some women will not fall ill. That is reality."

On the other hand, persons who did not or would not opt for PGD to have their children assessed PGD in a different way. Even if they expressed strong reservations about extending access to PGD for new indications, all of them admitted that there might be some wellcontrolled cases in which PGD might be a better way of having children.

Assessing the cases in which PGD might be considered a legitimate and better option for having a child often involved an evaluation of the severity of the disease. As shown in a previous article (Dekeuwer and Bateman, 2011), the persons we interviewed did not mobilize specific "subjective" criteria to this purpose; they often invoked the same "objective" criteria 
used by physicians. Thus, in discussing the acceptability of PGD for hereditary breast and ovarian cancer, some persons simply compared this late-onset cancer to cystic fibrosis, a disease that affects young children, or to Huntington's disease, a condition for which there is no treatment; the latter were considered more serious than the former and therefore justified recourse to PGD. Some also expressed their belief that medical progress would find a cure for breast and ovarian cancer. However, the severity of the disease was also assessed with regard to the way these criteria could be interpreted in terms of their personal and familial experience of the disease. This included its frequency in their family, the burden on family members of surveillance, prevention and eventually of treatment, and the distressing experience of caring for a sick relative and accompanying her death. As one woman said: “And why don't they allow it [PGD] here [in France]? Do they think we don't die enough?” Finally and above all, as shown in a preceding section, the severity of the disease and consequently the acceptability of undergoing PGD were assessed with regard to the way in which the preservation of health might interfere with the possibility of carrying out one's plan to have a family.

The persons we interviewed did not have an answer to the eugenic risk they associated with extension of PGD for cancer predisposition - nor do the best scholars, for that matter. But then this did not appear to be their main concern. As one woman mentioned, when one decides to have children, one risks transmitting "much more than a gene". Their reflections suggest that PGD can be considered a legitimate way of having children if it is primarily a means of avoiding the perpetuation of distressing life experiences that also may be an excessive burden on the family. And even when this view did not reflect a person's own views and choices regarding the moral acceptability of PGD, these persons did express the understanding that it might, for some people in particular cases, be the best option.

\section{Conclusion}


The small number of persons interviewed in this study, mostly women, is an obvious limitation of the findings presented here. Although we recruited only one male carrier, we felt it was pertinent to keep him in our sample for three reasons. The first is that he is the only person in the study to have effectively opted for PGD by going abroad to obtain it. The second is that his interview contains themes found in the women's interviews, because of the importance for carriers of their experience of the disease within their family. Finally, his interview could also be examined in the light of data on men presented in other studies. Indeed, as mentioned earlier, our study had an essentially exploratory objective, with the intent of examining in greater depth the impact of discovering carrier status on reproductive choices. Our study does confirms the strong presence of themes that have emerged in other studies, such as the familial dimension of the events and experiences surrounding genetic testing, and the strong sense of responsibility for other family members that motivates potential and effective carriers. But we do believe our findings generate new leads for future research in this area.

First of all, our findings highlight the impact of the harsh medical constraints and the uncertainty about the future on a carrier's thoughts about reproductive options. If our study shows no direct link between a woman's views regarding the acceptability of taking the risk of transmitting a deleterious mutation to the next generation and the fact that she has or has not developed cancer, it does show that her lived experience of the way the disease has affected her family and her close relatives as well as herself appears nonetheless to be crucial. Moreover, when these women and men are parents or are thinking about having a(nother) child, they are mainly concerned by the fact that they will be transmitting to their children the risk of going through the same painful experiences: fighting their own illness, witnessing the death of a close relative, or encountering difficulties in finding a partner or negotiating their 
plans for a family. Whether or not they take that risk will largely depend on whether or not they perceive these experiences as something with which they can cope.

Knowledge about how family relationships have held up in the past, opinions about what family life should be like, and feelings about one's duties to family members are all factors that contribute to the way women and men evaluate their capacity to cope. Moreover, when considering, for each particular decision to have a child, whether or not they wish to take the risk of transmitting these painful experiences, persons measure that risk against their commitment to and involvement in their plans to have a family. They consider how these plans may be challenged by the development of a tumor or by the medical constraints and personal difficulties encountered by persons with carrier status. They also consider how their initial conception of parental responsibilities and obligations, their role as care-givers, and their obligations to give their children the best chances in life and protect them from possible harm have or have not been disrupted by carrier status.

In such a context, persons who unambiguously preferred to avoid the risk of transmitting the mutation considered PGD a legitimate and morally acceptable option. A few women felt that the situation of a carrier of BRCA mutation was sufficiently manageable to make PGD unnecessary. Many, however, were undecided about this option and even felt quite uncomfortable with the idea of trying to avoid the risk of transmitting the mutation. Indeed, quite a few women felt that they should not interfere with something that transcends their own existence and that some of them called "destiny". Nonetheless, whatever their personal position, almost everyone we interviewed understood that persons with a particularly painful experience of the disease might wish to choose PGD as a reproductive option and that they would be justified in doing so. 


\section{Funding Acknowledgements}

This work was supported by the Agence de la Biomédecine [Cancer héréditaires et procréation]; and the Fondation de France [grant number 2008001085].

\footnotetext{
${ }^{1}$ The Agence de la Biomédecine was created by the French bioethics law of 6 August 2004 to administrate four domains of activity: organ, tissue and cell transplantation, reproduction, embryology and human genetics. It functions under the authority of the French Ministry of Health.

${ }^{2}$ The French National Cancer Institute, created by a law on public health policy promulgated on 9 August 2004, is a public health and research agency. It has two basic mandates: to develop expertise on cancer and to program, evaluate, and finance research projects.

${ }^{3}$ Code de la Santé Publique (Public Health Law), Art L. 2131-4 (disposition added by the French bioethics law of 6 August 2004).

${ }^{4}$ Women carriers face a cumulative risk of breast cancer estimated at $50-70 \%$ by the age of 70 and a risk of ovarian cancer estimated at $10-40 \%$ by the age of 70 (Stoppa-Lyonnet et al., 2008). Men also face a cumulative risk of developing breast cancer, estimated at not more than $7 \%$, as well as an increased risk of developing prostate cancer (Levy-Lahad and Friedman, 2007).

${ }^{5}$ PND is not considered an appropriate option in France in that it allows parents who eventually decide not to terminate the pregnancy to know from birth whether or not the child carries the mutation. The child would not have the option as an adult of not knowing his or her status.

${ }^{6}$ Our interview and data collection procedure was reviewed and authorized by the Commission Nationale de l'informatique et des libertés (CNIL).

${ }^{7}$ Participation rate was fairly good at one of the two hospitals, where patients often returned for surveillance or cancer treatment following genetic testing (about 1 out of every 2). At the second hospital, participation rate was much lower, probably because surveillance was carried out at a different institution.
} 


\section{References}

d'Agincourt-Canning, L. 2005. The Effect of Experiential Knowledge on Construction of Risk Perception in Hereditary Breast/Ovarian Cancer. Journal of Genetic Counseling 14 (1): 55-69.

d'Agincourt-Canning, L. and P. Baird. 2006. Genetic testing for hereditary cancers: The impact of gender on interest, uptake and ethical considerations. Critical Reviews in Oncology/Hematology 58 (2): 114-123.

Dekeuwer, C. and S. Bateman. 2011. Que dois-je transmettre à mes enfants ? Gravité des maladies héréditaires et choix procréatifs. In Éthique et Famille (tome 2), ed. E. RudeAntoine et M. Pievic, 143-163. L'Harmattan, Paris.

Fortuny, D. et al. 2009. Opinion about reproductive decision making among individuals undergoing BRCA1/2 genetic testing in a multicentre Spanish cohort. Human Reproduction 24 (4): 1000-6.

Hallowell, N. et al. 2003. Balancing autonomy and responsibility: the ethics of generating and disclosing genetic information. Journal of Medical Ethics 29 (2): 74-79.

Hallowell, N. et al. 2005. Men's Decision-Making about Predictive BRCA1/2 Testing: The Role of Family. Journal of Genetic Counseling 14 (3): 207-217.

Hallowell, N. et al. 2006. Guilt, blame and responsibility: men's understanding of their role in the transmission of BRCA1/2 mutations within their family. Sociology of Health and Illness 28 (7): 969-988.

Levy-Lahad, E. and E. Friedman. 2007. Cancer risk among BRCA1 and BRCA2 mutation carriers. British Journal of Cancer 96 (1): 11-15. 
Menon, U. et al. 2007. Views of BRCA gene mutation carriers on preimplantation genetic diagnosis as a reproductive option for hereditary breast and ovarian cancer. Human Reproduction 22 (6): 1573-1577.

Pagani, O. et al. 2011. Pregnancy after breast cancer: if you wish, ma'am. Breast Cancer Research and Treatment, DOI: 10.1007/s10549-011-1643-7. Published online: 23 June.

Quinn, G.P. et al. 2009. Conflict between values and technology: perceptions of preimplantation genetic diagnosis among women at increased risk for hereditary breast and ovarian cancer. Familial Cancer 8 (4): 441-9.

Quinn, G.P. et al. 2010a. High risk men's perceptions of pre-implantation genetic diagnosis for hereditary breast and ovarian cancer. Human Reproduction 25 (10): 2543-50.

Quinn, G.P. et al. 2010b. BRCA carriers' thoughts on risk management in relation to preimplantation genetic diagnosis and childbearing: when too many choice are just a difficult as none. Fertility and Sterility 94 (6): 2473-2475.

Rowley, E. 2008. On doing 'being ordinary': women's accounts of BRCA testing and maternal responsibility. New Genetics and Society 26 (3): 241-250.

Staton, A.D. et al. 2008. Cancer risk reduction and reproductive concerns in female BRCA1/2 mutation carriers. Familial Cancer 7 (2): 179-186.

Stoppa-Lyonnet, D. et al. 2008. Diagnostic prénatal, interruption médicale de grossesse, diagnostic préimplantatoire et formes héréditaires de cancers. Rapport rédigé à la demande de l'Agence de la Biomédecine et Institut National du Cancer. Avril 2008, 64 pp. http://www.agence-biomedecine.fr/professionnels/rapports-et-etudes-realises-autour-de-1activite-de-dpi.html . Accessed 27 July 2011.

Strømsvik, N. et al. 2009. Men in the women's world of hereditary breast and ovarian cancer — a systematic review. Familial Cancer 8: 221-229. 
Strømsvik, N. et al. 2010. Stigmatization and male identity: Norwegian males' experience after identification as BRCA1/2 mutation carriers. Journal of Genetic Counseling 19 (4): 360370. 
Table 1: Demographic profile of twenty mutation carriers

Sex:

Female $\quad 19$

Male 1

Age

30-39 10

$40-49 \quad 5$

$50-59 \quad 4$

$60+\quad 1$

Marital Status

Single 1

Living with a partner 6

Married 10

Divorced 3

Offspring

None 5

One $\quad 6$ (of which 2 women with ongoing second pregnancy)

Two 8

Three 1

Personal history of hereditary breast and ovarian cancer

None 11

Breast cancer 8

Ovarian cancer $\quad 1$

Time at interview since test result

1 year 6

2 years 1

3 years 3

4 years 4

5 years $\quad 0$

6 years 3

7 years 1

10 years $+\quad 2$ 